\title{
Is more always better? An exploration of the differential effects of functional integration on performance in new product development
}

\author{
J.F.S. Gomes ${ }^{\text {a,**}}{ }^{*}$ P.C. de Weerd-Nederhof ${ }^{\mathrm{a}}$, A.W. Pearson ${ }^{\mathrm{b}}$, M.P. Cunha ${ }^{\mathrm{c}}$ \\ a Faculty of Technology and Management, University of Twente, P.O. Box 217, Enschede 7500 AE, The Netherlands \\ ${ }^{\mathrm{b}}$ Manchester Business School, University of Manchester, Booth Street West, Manchester M15 6PB, UK \\ c Faculdade de Economia, Universidade Nova de Lisboa, Rua Marques de Fronteira, 20, Lisbon 1099-038, Portugal
}

Received 27 June 2001; accepted 22 October 2001

\begin{abstract}
The objective of this paper is to explore the relationship between performance in new product development (hereinafter NPD) and functional integration under different conditions of project uncertainty. Functional integration is conceived as a two-dimensional concept, encompassing a behavioural - collaboration - and a structural — interaction - dimension.

This study is based on 92 questionnaires looking at NPD activities in more than 40 British and Dutch companies from various industrial sectors. The results suggest that the nature of the relationship between integration and performance is contingent upon the project stage and the degree of novelty in the new product. Integration in the initial stages of the project assumes a prominent role in the quality of the end product, whereas in later stages it is more associated with time to market than with costs and end product quality. Results further show that the dimension collaboration of integration may be more relevant under circumstances of high new product innovativeness than when minor variations are introduced in a new product. The paper ends with a discussion of the use of universal approaches to NPD management.
\end{abstract}

(C) 2002 Elsevier Science Ltd. All rights reserved.

Keywords: New product development; Integration; Contingent approach; Project performance; Innovation

\section{Introduction}

Numerous studies have shown that functional integration is a critical aspect of today's new product development (NPD) activities (Gupta et al. 1985, 1986; Souder and Moenaert, 1992; Song et al., 1997). As far back as 1970, Allen observes that the frequency, the structure of communication networks, and the nature of communicational mechanisms differ sharply between low and high performers in R\&D organisations (Allen, 1970). More recently, Calantone et al. (1995) reviewed 500 articles and books on NPD, innovation, and general management, and suggest that the quality of the market-

\footnotetext{
* Corresponding author. Present address: ISPA-Instituto Superior de Psicologia Aplicada, R. Jardim do Tabaco, 44, Lisbon 1100, Portugal. Tel.: +351-21881-1700; fax: +351-21886-0954.

E-mail addresses: jorge_rd_gomes@ hotmail.com (J.F.S. Gomes), p.c.deweerd-nederhof@sms.utwente.nl (P.C. de Weerd-Nederhof), apearson@man.mbs.ac.uk (A.W. Pearson), mpc@fe.unl.pt (M.P. Cunha).
}

ing-R\&D interface is one of the current concerns in NPD research. Also in Europe the interface management is regarded as a very important issue for current research (Brockoff and Pearson, 2000). Similarly, Griffin and Hauser (1996) elucidate that communication between marketing and $R \& D$ is related to success, regardless of the focus on services or products, and on consumer or industrial markets. This relationship is especially critical when the degree of uncertainty in the environment is high.

The central question raised by research on integration is that NPD is a process that requires the capability to obtain, process and interpret large amounts of market, technical, financial and other information, in order to develop product ideas and evaluate their technical soundness, manufacturability and economic feasibility. This requires organisations and individuals to be able to overcome internal differences and barriers built during the process of differentiation (Lawrence and Lorsch, 1967; Dougherty, 1992; Griffin and Hauser, 1996), and implement an NPD process based on collaboration of structurally separated, yet interdependent, functional units. 
Conceiving of the innovation process this way means that along with diversity of information and tasks to be performed, there is also diversity of behaviours and attitudes, as projects usually require the contribution of many people with different roles in the process. The problem of integrating tasks and activities becomes as well one of integrating attitudes and behaviours.

The objective of the present paper is to explore the relationship between performance in NPD and integration of tasks and activities, on one hand, and of behaviours, on the other. Furthermore, it aims to explore the nature of this relationship under different conditions of project uncertainty.

Previous research has examined the bi-dimensional nature of functional integration (e.g. Kahn, 1996), but this has been done at a departmental level. This paper complements existing literature by focusing on the marketing-R\&D integration at the project level of analysis. It starts by reviewing definitions of integration and the effect of integration practices on performance. It then presents the method and results of the empirical study and it concludes with discussion and implications for managers and researchers involved in NPD activities.

\section{Literature review}

The concept of integration has been coloured with different and various meanings. Authors have tried to organise this diversity by describing types or levels of integration. For instance, Mintzberg et al. (1996) distinguish between inter-organisational and intra-organisational collaboration. The first one is concerned with collaboration among people and across units, whereas the second includes upstream (e.g. suppliers), downstream (e.g. franchises), Governmental, and lateral (e.g. shared research projects) collaboration. The current work recognises the recent trend in the study of external collaboration, but focuses only on internal integration of functional units or departments in the context of NPD.

Functional integration has also been labelled: interface (e.g. Gupta et al., 1986), cooperation (e.g. Pinto and Pinto, 1990), co-ordination (e.g. Scott, 1998), collaboration (e.g. Jassawalla and Sashittal, 1998), communication (Pearson and Ball, 1993), and cross- or multifunctional teams (e.g. Denison et al., 1996). In the project management literature it is common to find terms such as concurrent or simultaneous engineering, integrated design and engineering, or design for manufacturing (e.g. Hauptman and Hirji, 1999). One common aspect between these terms is that they all stress the crucial interplay between human and organisational systems in NPD activities.

However, they also emphasise distinct aspects of integration. Kahn (1996) suggests that definitions of integration have focused on two attributes: interaction and collaboration. The first term emphasises the use and exchange of communication between functional units; it represents the structural nature of cross-departmental activities. Collaboration focuses on the collective work between departments; it represents the unstructured, affective nature of interdepartmental relationships. Based on questionnaires to 514 marketing, R\&D, and manufacturing managers, Kahn (1996) found that collaboration has a stronger effect on product development and process development performance than interaction.

Hauptman and Hirji (1999) argue that collaboration is needed to overcome the negative attitudes and behaviours that result from differentiation and specialisation and to support cooperation and productive conflict resolution. Co-ordination is also needed to ensure timely sequencing, scheduling and synchronisation of interdependent activities. The operational definitions used by these authors are different from those used by Kahn (1996): integration mechanisms are a measure of status parity, job rotation, and group based rewards; co-ordination mechanisms are a measure of project leader's power and use of communication technologies and tools. Based on questionnaires to 50 cross-national project teams, the authors found that both types of mechanisms support an effective team process and help to overcome the negative effects due to geographic distance and time differences.

Developing grounded theory from a study of 10 hightech firms, Jassawalla and Sashittal (1998) built on Kahn's work to propose that cross-functional collaboration goes beyond integration. While cross-functional teams and concurrent engineering teams are some of the key structural mechanisms to achieve integration, collaboration reflects specific attributes of team members and their organisational context. Collaborative firms score high in attributes such as transparency (a condition of high awareness achieved as a result of intense communication and exchange of hard-data) and mindfulness (a condition where new product decisions and participants' actions reflect an integrated understanding of the motivations, agendas, and constraints of all participants). Collaboration is attained only after integration has been achieved. The authors did not include performance measures in their study.

Finally, in a case study of implementation of a structured NPD process at Texas Instruments, Bernasco et al. (1999) observed that meetings, committees and telephone calls improve interaction, but not necessarily collaboration. Collaboration is improved by sharing goals, mutual understanding and informal activity. The authors further suggest that managers use interaction for establishing contact and familiarity between departments; collaboration will slowly emerge from this process.

Not all these studies address the relationship between performance and integration; some (e.g. Jassawalla and Sashittal, 1998) explore the integration mechanisms only 
and do not look at performance. Similarly, Hauptman and Hirji (1999) explore the integration mechanisms, but not functional integration per se. Kahn (1996) and Bernasco et al. (1999) concentrate on interdepartmental integration, and not on integration at the level of the NPD project. Other contributions to the study of the relationship between functional integration and performance tend to focus on one of its dimensions only; for example, Gupta and colleagues (Gupta et al. 1985, 1986) and Song and colleagues (Song and Parry, 1992; Song et al., 1998) have mainly examined the interaction side of integration, which is defined as joint involvement between functional departments in a number of activities intimately related to NPD. Conversely, most of the works by Souder, Moenaert, and associates (Souder, 1988; Moenaert et al., 1994), Pinto and Pinto (1990), Dougherty (1992) and Pinto et al. (1993), have extensively looked at the collaboration part of the concept, but have not considered interaction of activities. Both groups of authors tend to adopt a quantitative position by using well-established measures (e.g. questionnaire application to R\&D and marketing managers).

On the other hand, recent research suggests that high levels of integration is not always desirable or achievable, and that its relationship with other variables might depend on factors such as product complexity or product innovativeness (Kamoche and Cunha, 2000; WeerdNederhof, 1998). These ideas remain largely unexplored.

Furthermore, most of the abovementioned research has been conducted in the American and Japanese contexts. Some exceptions are the works of Moenaert et al. (1994) (Belgian companies) and Hauptman and Hirji (1999) (various European countries).

In sum, despite the knowledge accumulated on the topic, there is a need to further explore the relationship between performance and the marketing-R\&D integration in its components of collaboration and interaction, as well as to assess the effect of contingency factors on that relationship; moreover, this needs to be done in an European setting, where differences in organisation culture may introduce new elements yet to understand. The current paper follows the quantitative tradition of Gupta et al. (1985, 1986), Song and Parry (1992) and Kahn (1996).

\section{Method}

\subsection{Sample}

The data for this study comes from questionnaires to 92 managers directly involved in NPD activities in more than 40 British and Dutch companies from various industrial sectors: chemicals, pharmaceutical, homecare and personal care, electronics and telecommunications, building materials, and white goods. The questionnaires were collected in two different ways. A first group of questionnaires was mailed to $325 \mathrm{R} \& \mathrm{D} / \mathrm{NPD}$ managers; this resulted in 47 returned questionnaires $(14.4 \%$ return rate), of which 39 had good quality data. A second group of 68 questionnaires was handed over directly to NPD managers, as part of a bigger project in which was also collected a variety of qualitative data. As expected, the return rate in the second group was considerably higher: $61-89 \%$ questionnaires were returned, although only 53 had good quality data (e.g. completed scales). $t$-Tests for independent samples did not reveal statistical differences between the two groups in the majority of the variables. There were no differences between the British and the Dutch groups either.

\subsection{Measures}

With the exception of product innovativeness, all variables were measured on a 5-point Likert scale. The measures were adapted from those developed by a number of authors:

(a) Functional integration: interaction (scale adapted from Gupta et al., 1985; Song and Parry, 1992). The items of this scale measure interaction in 18 activities that require involvement between marketing and $R \&$ D during an NPD project. These activities can further be grouped into five areas of integration between R\& $\mathrm{D}$ and marketing: budgeting; planning and scheduling; concept generation and screening; product development, testing and commercialisation; and post-commercialisation monitoring and service. Respondents were asked to rate on a scale from 1 'very low' to 5 'very high' the level of interaction in the activity concerned. Scores for the overall measure of interaction are obtained by averaging the responses given to the 18 items.

(b) Functional integration: collaboration (scale adapted from Pinto and Pinto, 1990). The 15 items on this scale measure three dimensions of cooperation: interpersonal relations, communication and task orientation. Respondents were asked to rate on a scale from 1 'strongly disagree' to 5 'strongly agree' the extent to which each of the sentences best described what happened during the particular project. Scores for each sub-scale and for the overall measure of cooperation are obtained by averaging the responses given to the correspondent items.

(c) Degree of product innovativeness: following Dougherty (1992), products can be classified according to their degree of innovativeness in five areas: applications, market segments, distribution, technology, and manufacturing. Based on these areas, a dichotomous scale was created: low and high innovative products (where the 'high group' reflects innovation in at least two of the areas). 
(d) Outcome measures: six items were adapted from works by Pinto and Pinto (1990), Song and Parry (1992) and Song et al. (1998), to measure the degree to which the goals of time to market, cost, and product quality were attained in the particular project. Factor analysis to the six items showed three distinct factors, therefore providing support for the scale's construct validity. A value of 1 in the time scale indicates that the product was launched before time; 5 indicates that the project took longer to go to market. A value of 1 in the cost scale indicates that the product cost less than budgeted; 5 indicates that the project cost more than predicted. A result of 1 in the quality scale indicates that the final product was of lower quality than expected; 5 indicates that the product was of higher quality than expected.

\section{Results}

A first set of descriptive analysis was conducted on the data. Table 1 presents means and standard deviations for the variables of interest in the two groups of questionnaires and the overall group. In addition, it also shows reliability estimates for the scales.

Generally speaking, internal consistency coefficients are acceptable (Nunnally and Bernstein, 1996). On an average, respondents score higher on the collaboration sub-scales than on the interaction ones. Interpersonal relations scores higher amongst all sub-scales, with budgeting and post-commercialisation monitoring achieving the lowest mean values of all scales. Respondents also report that projects are on time, on costs, and hit expectations in terms of product quality.

Table 1

Instruments' quality and descriptive statistics

\begin{tabular}{lll}
\hline & $\alpha$ (No. items) & Mean (SD) \\
\hline $\begin{array}{l}\text { Functional integration: interaction } \\
\text { total }\end{array}$ & $0.84(18)$ & $3.3(0.62)$ \\
Budgeting & $0.64(2)$ & $3.1(0.91)$ \\
Planning & $0.60(2)$ & $3.5(0.81)$ \\
Concept generation & $0.80(6)$ & $3.4(0.76)$ \\
Product development & $0.74(5)$ & $3.2(0.72)$ \\
Post-commercialisation monitoring & $0.60(3)$ & $3.1(0.92)$ \\
Functional integration: collaboration & $0.87(14)$ & $3.8(0.51)$ \\
total & & \\
Interpersonal relations & $0.82(5)$ & $4.0(0.63)$ \\
Communication & $0.70(4)^{\mathrm{a}}$ & $3.8(0.67)$ \\
Task orientation & $0.68(5)$ & $3.6(0.56)$ \\
Time for development & $0.57(2)$ & $2.8(0.86)$ \\
Cost & $0.68(2)$ & $3.0(1.0)$ \\
Quality of end product & $0.61(2)$ & $3.5(0.71)$ \\
\hline
\end{tabular}

a One item was eliminated from the scale and from subsequent analysis due to its bad performance both in reliability and factor analysis.
Table 2 displays the correlation coefficients between the two dimensions of functional integration: interaction and collaboration.

The results show that collaboration correlates higher with interaction in the initial stages of the NPD process than with later stages. The higher the degree of interaction between R\&D and marketing in the budgeting and in the planning and scheduling stages, the more collaborative are the behaviours and attitudes of those involved in NPD projects and the higher the degree of communication between them.

The stage in which product development, testing and commercialisation are carried out is not correlated at all with the collaboration scales, which indicates that respondents do not feel that collaboration between $\mathrm{R} \& \mathrm{D}$ and marketing people is important during product development.

Table 3 shows the pattern of correlations between the interaction and collaboration scales, and the performance variables.

The correlation coefficients are weak to medium, with the interaction scales scoring the highest values amongst all. The collaboration scales show very weak or even inexistent association with the performance measures. Quality is significantly correlated with interaction in the initial stages of the NPD process, whereas time seems to be more important for interaction in the later stages (negative correlations in the present case means that the higher the interaction the less time it takes to launch a new product).

The pattern of correlations changes if the analysis is broken down by degree of product innovativeness. Table 4 contrasts the correlation patterns between high and low innovative products.

As it can be observed from the table, the inclusion of degree of innovativeness propels up correlation values and changes dramatically the relationship between the collaboration scales and the performance measure of cost. Time to market and quality of end product seem to be associated with interaction when products have a low degree of innovativeness, but not for more innovative products. However, for more innovative products, collaboration amongst team members seems to be important especially for reducing costs of development.

Likewise, when regression analysis is performed, indices improve if the degree of innovativeness is taken into account. Table 5 shows regression results for the three performance measures for the overall group and by degree of innovativeness.

Regression results are generally very low but tend to improve when analysis is performed according to the degree of product innovativeness. As in the correlation analysis, interaction tends to contribute more than collaboration for explaining time and quality, whereas collaboration appears to have an effect on cost for high innovative products. 
Table 2

Correlation matrix of interaction versus collaboration $(* p<0.05)$

\begin{tabular}{lllll}
\hline & Interpersonal relations & Communication & Task orientation & Collaboration total \\
\hline Budgeting & 0.17 & $0.25^{*}$ & $0.23^{*}$ & $0.24^{*}$ \\
Planning & 0.20 & $0.26^{*}$ & 0.14 & $0.23^{*}$ \\
Concept generation & 0.11 & 0.08 & 0.21 & 0.15 \\
Product development & 0.09 & 0.06 & 0.08 & 0.09 \\
Post-commercialisation & 0.10 & 0.01 & 0.21 & 0.15 \\
Interaction total & 0.17 & 0.11 & $0.25^{*}$ & 0.21 \\
\hline
\end{tabular}

Table 3

Correlation matrix of integration versus performance $(* p<0.05)$

\begin{tabular}{lccc}
\hline & Time & Cost & Quality \\
\hline Budgeting & -0.02 & -0.09 & 0.16 \\
Planning & -0.14 & 0.09 & $0.28^{*}$ \\
Concept generation & -0.21 & $-0.27^{*}$ & $0.24^{*}$ \\
Product development & $-0.33^{*}$ & -0.16 & 0.21 \\
Post-commercialisation & $0.32^{*}$ & -0.20 & -0.15 \\
Interaction total & $-0.30^{*}$ & -0.21 & $0.29^{*}$ \\
Interpersonal relations & -0.08 & -0.17 & 0.09 \\
Communication & -0.05 & 0.14 & 0.07 \\
Task orientation & -0.04 & 0.00 & 0.21 \\
Collaboration total & -0.06 & -0.14 & 0.16 \\
\hline
\end{tabular}

\section{Discussion and conclusions}

Despite the low values found for both the correlation and regression analysis, these are comparable to those reported by other authors. For example, the standardised path coefficient estimates between cooperation and performance in the study of Song et al. (1997) vary between 0.22 and 0.38. Pinto and Pinto (1990) report an adjusted $R^{2}$ of 0.29 between cooperation and task outcomes. And the regression coefficients described by Kahn (1996) vary between 0.01 and 0.14 . If on one hand these low values - yet statistically significant - indicate that other variables not included in this study help to explain the variance of performance measures - as indeed suggested by Brown and Eisenhardt (1995) —, they also show that functional integration is associated with time, cost, and quality.

Overall, the results of this investigation confirm those of several authors that have looked at the relationship between functional integration and process and product performance (e.g. Dougherty, 1992; Pinto et al., 1993; Moenaert et al., 1994; Griffin and Hauser, 1996). However, the findings also suggest that integration is a multidimensional construct, which relates differently to outcomes in NPD. Firstly, interaction between marketing and R\&D in the initial stages of the NPD process seems to assume a prominent role in the quality of the end product, whereas interaction in later stages appears to be more associated with time to market than with costs and quality of the end product. These results give partial support to Verganti (1997) and Song et al. (1998): in both studies it was found that integration in the concept generation stage contributes to better product effectiveness and product efficiency. Secondly, although collaboration has been advocated as having a more important impact of performance than interaction (Kahn, 1996), the current research has shown opposite results. A possible reason for this disparity might be related to the different operational definitions used in this study and in Kahn's work. For example, Kahn (1996) uses mechanisms of communication for measuring interaction, whereas the

Table 4

Correlation matrix of integration versus performance - low and high product innovativeness $(* p<0.05)$

\begin{tabular}{|c|c|c|c|c|c|c|}
\hline & \multicolumn{2}{|l|}{ Time } & \multicolumn{2}{|l|}{ Cost } & \multicolumn{2}{|c|}{ Quality } \\
\hline & Low & High & Low & High & Low & High \\
\hline Budgeting & 0.03 & -0.11 & -0.12 & -0.11 & 0.30 & 0.00 \\
\hline Planning & -0.27 & -0.03 & 0.07 & 0.12 & $0.31 *$ & 0.23 \\
\hline Concept generation & -0.32 & -0.14 & -0.23 & $-0.37 *$ & $0.41 *$ & 0.05 \\
\hline Product development & $-0.38^{*}$ & -0.31 & -0.16 & -0.15 & 0.15 & 0.29 \\
\hline Post-commercialisation & $-0.46^{*}$ & -0.25 & $-0.36^{*}$ & -0.04 & $0.35^{*}$ & -0.03 \\
\hline Interaction total & $-0.39 *$ & -0.26 & -0.24 & -0.19 & $0.38^{*}$ & 0.15 \\
\hline Interpersonal relations & -0.04 & -0.17 & -0.04 & $-0.41 *$ & 0.09 & 0.07 \\
\hline Communication & -0.01 & -0.14 & 0.06 & $-0.44 *$ & 0.08 & 0.02 \\
\hline Task orientation & 0.09 & -0.22 & 0.16 & -0.30 & $0.33 *$ & 0.01 \\
\hline Collaboration total & 0.00 & -0.21 & 0.06 & $-0.47^{*}$ & 0.23 & 0.04 \\
\hline
\end{tabular}


Table 5

Regression analysis - Beta coefficients and $(t$-values $)(* p<0.05 \mathrm{~ns}=$ no statistical differences found $)$

\begin{tabular}{lllcc}
\hline & Model & $R^{2}$ & Interaction & Collaboration \\
\hline \multirow{2}{*}{ PD time } & Overall group & 0.09 & $-0.31(-2.67 *)$ & $0.01(0.08 \mathrm{~ns})$ \\
& Low innovativeness & 0.19 & $-0.47(-2.78 *)$ & $0.21(1.24 \mathrm{~ns})$ \\
& High innovativeness & 0.11 & $-0.27(-1.67 \mathrm{~ns})$ & $-0.22(-0.22 \mathrm{~ns})$ \\
PD cost & Overall group & 0.05 & $-0.19(-1.68 \mathrm{~ns})$ & $-0.10(-0.88 \mathrm{~ns})$ \\
& Low innovativeness & 0.09 & $-0.31(-1.90 \mathrm{~ns})$ & $0.18(1.11 \mathrm{~ns})$ \\
& High innovativeness & 0.26 & $-0.21(-1.43 \mathrm{~ns})$ & $-0.47(-3.22 *)$ \\
End product quality & Overall group & 0.10 & $0.26(2.30 *)$ & $0.13(1.15 \mathrm{~ns})$ \\
& Low innovativeness & 0.17 & $0.33(2.05 *)$ & $0.15(0.94 \mathrm{~ns})$ \\
& High innovativeness & 0.02 & $0.15(0.87 \mathrm{~ns})$ & $0.05(0.29 \mathrm{~ns})$ \\
\hline
\end{tabular}

current study used NPD activities that are likely to require integration between functional units.

Finally, this research provides evidence that the degree of product innovativeness plays an important role in understanding the benefits of intra-organisational collaboration during NPD. As shown, collaboration may be more relevant under circumstances of high new product innovativeness than when minor variations are introduced in a new product. As such, these findings suggest that a universal approach to the management of NPD may not be possible. As argued by Kamoche and Cunha (2000), more than insisting on the benefits of a one best way, researchers should analyse how different contingencies recommend the adoption of different NPD configurations. Moreover, it is anticipated that the traditional sequential models (e.g. Cooper 1988, 1990) may be useful for 'routine innovations', but not for the development of new products with a higher degree of innovativeness.

The data further shows that interaction may be beneficial for less innovative new products, while collaboration may be necessary while developing highly new products. This can be explained by the type of activities involved in both kinds of projects: more structure can be used in the first case; less structure and a need for sense making require collaboration in the latter. Therefore, this research suggests that the challenges posed by different types of products may be fundamental not only for understanding the paths for NPD, but also for designing NPD activities which adapt to the type of product. With regard to this, existing product typologies (e.g. Pinto and Covin, 1989; Coombs et al., 1998) could be used to increase knowledge in the field.

Recent research (e.g. Brown and Eisenhardt 1995, 1997) proposes that unconventional development practices such as extensive communication, loose structuring, and fluid job descriptions, are fundamental ingredients in NPD projects, which confirms that more collaboration may be necessary when a new path must be discovered, while more interaction may be recommended for developing minor innovations. These results fundamentally reflect the divergence between exploration and exploitation, and confirm that more is better if such a divergence is considered.

\section{Acknowledgements}

The authors wish to thank all the managers who provided data for the study. Coen van Gassen is gratefully acknowledged for assisting in the data gathering, and Olaf Fisscher for facilitating the joint research. Portions of the research that contributed to the writing of this paper were supported by grants from RADMA (Research and Development Management Association, England) and FCT (Fundação para a Ciência e Tecnologia, Portugal).

\section{References}

Allen, T.J., 1970. Communication networks in research and development laboratories. R\&D Management 1, 14-21.

Bernasco, W., Weerd-Nederhof, P.C., Tillema, H., Boer, H., 1999. Balanced matrix structure and new product development process at Texas Instruments Materials and Controls Division. R\&D Management 29 (2), 121-131.

Brockoff, K.K., Pearson, A.W., 2000. Technology managementwhere do we stand. In: Brockoff, K.K., Pearson, A.W., WeerdNederhof, P.C.DE, Kerssens-van Drongelen, I.C. (Eds.), Readings Technology in Management. Twente University Press, Enschede, pp. 9-21.

Brown, S.L., Eisenhardt, K.M., 1995. Product development: past research, present findings, and future directions. Academy of Management Review 20 (2), 343-378.

Brown, S.L., Eisenhardt, K.M., 1997. The art of continuous change: linking complexity theory and time-paced evolution in relentlessly shifting organizations. Administrative Science Quarterly 42, 1-34.

Calantone, R.J., Di Benedetto, C.A., Haggblom, T., 1995. Principles of new product management: exploring the beliefs of product practitioners. Journal of Product Innovation Management 12, 235-247.

Coombs, R., McMeekin, A., Pybus, R., 1998. Toward the development of benchmarking tools for R\&D project management. R\&D Management 28 (3), 175-186.

Cooper, R.G., 1988. The new product process: a decision guide for management. Journal of Marketing Management 3 (3), 238-258. 
Cooper, R.G., 1990. Stage-gate systems: a new tool for managing new products. Business Horizons 33 (3), 44-54.

Denison, D.R., Hart, S.L., Kahn, J.A., 1996. From chimneys to crossfunctional teams: developing and validating a diagnostic model. Academy of Management Journal 39 (4), 1005-1019.

Dougherty, D., 1992. Interpretative barriers to successful product innovation in large firms. Organization Science 3 (2), 179-202.

Griffin, A., Hauser, J.R., 1996. Integrating R\&D and marketing: a review and analysis of the literature. Journal of Product Innovation Management 13, 191-215.

Gupta, A.K., Raj, S.P., Wilemon, D., 1985. The R\&D-marketing interface in high-technology firms. Journal of Product Innovation Management 2, 12-24.

Gupta, A.K., Raj, S.P., Wilemon, D., 1986. A model for studying R\&D-marketing interface in the product innovation process. Journal of Marketing 50 (2), 7-17.

Hauptman, O., Hirji, K.K., 1999. Managing integration and coordination in cross-functional teams: an international study of concurrent engineering product development. R\&D Management 29 (2), 179-191.

Jassawalla, A.R., Sashittal, H.C., 1998. An examination of collaboration in high-technology new product development processes. Journal of Product Innovation Management 15 (3), 237-254.

Kahn, K.B., 1996. Interdepartmental integration: a definition with implications for product development performance. Journal of Product Innovation Management 13 (2), 137-151.

Kamoche, K., Cunha, M.P., 2000. Minimal structures: from jazz improvisation to product innovation. Organization Studies 22 (5), 733-764.

Lawrence, P.R., Lorsch, J.W., 1967. Organization and Environment. Harvard Business Review Press, Boston.

Mintzberg, H., Dougherty, D., Jorgensen, J., Westley, F., 1996. Some surprising things about collaboration - knowing how people connect makes it work better. Organizational Dynamics 25 (1), 60-71.

Moenaert, R.K., Souder, W.E., De Meyer, A., Deschoolmeester, D., 1994. R\&D-marketing integration mechanisms, communication flows, and innovation success. Journal of Product Innovation Management 11, 31-45.

Nunnally, J.C., Bernstein, I.H., 1996. Psychometric Theory, 3rd ed. McGraw-Hill, New York.

Pearson, A.W., Ball, D.F., 1993. A framework for managing communication at the $\mathrm{R} \& \mathrm{D} /$ marketing interface. Technovation 13 (7), 439-447.

Pinto, J.K., Covin, J.G., 1989. Critical factors in project implementation: a comparison of construction and R\&D projects. Technovation 9, 49-62.

Pinto, M.B., Pinto, J.K., 1990. Project team communication and crossfunctional cooperation in new product development. Journal of Product Innovation Management 7 (3), 200-212.

Pinto, M.B., Pinto, J.K., Prescott, J.E., 1993. Antecedents and consequences of project team cross-functional cooperation. Management Science 39 (10), 1281-1297.

Scott, G.M., 1998. The new age of new product development: are we there yet? R\&D Management 28 (4), 225-236.

Song, X.M., Parry, M.E., 1992. The R\&D-marketing interface in Japanese high-technology firms. Journal of Product Innovation Management 9, 91-112.

Song, X.M., Montoya-Weiss, M.M., Schmidt, J.B., 1997. Antecedents and consequences of cross-functional cooperation: a comparison of $\mathrm{R} \& \mathrm{D}$, manufacturing, and marketing perspectives. Journal of Product Innovation Management 14 (1), 35-47.

Song, X.M., Thieme, R.J., Xie, J., 1998. The impact of cross-functional joint involvement across product development stages: an exploratory study. Journal of Product Innovation Management 15, 289303.
Souder, W.E., 1988. Managing relations between R\&D and marketing in new product development projects. Journal of Product Innovation Management 5 (1), 6-19.

Souder, W.E., Moenaert, R.K., 1992. Integrating marketing and R\&D project personnel within innovation projects: an information uncertainty model. Journal of Management Studies 29 (4), 485-512.

Verganti, R., 1997. Leveraging on systemic learning to manage the early phases of product innovation projects. R\&D Management 27 (4), 377-392.

Weerd-Nederhof, P.C. de., 1998. New product development systems: operational effectiveness and strategic flexibility. Thesis University of Twente, Enschede, the Netherlands.

Jorge F.S. Gomes is Assistant Professor at the Instituto Superior de Psicologia Aplicada of Lisbon, Portugal, where he teaches undergraduate and postgraduate courses on Organisational Behaviour and Research Methods, and Visiting Researcher at the University of Twente in the Netherlands. He received a PhD in Business Administration from the Manchester Business School, England. His research interests include the management of innovation and knowledge, and the structuring of innovation teams in an organisational environment. He has published in the journals International Journal of Management Review, Comportamento Organizacional e Gestão, Bedrijfskundig Vakblad, and Revista Portuguesa de Gestão, and at the present moment has several forthcoming papers in other international journals.

Petra C. de Weerd-Nederhof is Associate Professor of New Product Development at the University of Twente in the Netherlands. She holds an MSc in Industrial Engineering and a $\mathrm{PhD}$ in Management Studies from the same university. The $\mathrm{PhD}$ thesis is entitled "New Product Development Systems: Operational Effectiveness and Strategic Flexibility". She is currently working on the development of a design methodology for organising NPD systems for improved Strategic Flexibility. Her current research interests include the management and organisation of NPD, R\&D and innovation, concurrent engineering, knowledge management and performance assessment/measurement in NPD and R\&D. De Weerd teaches undergraduate courses in Organisation Theory and Innovation Management and postgraduate seminars in New Product and Process Development. She is the (co-)author of a number of articles which have been published in, among others, R\&D Management and the International Journal of Innovation Management. She is also involved in the organisation of the R\&D Management Conferences and the European Doctoral SummerSchools in Technology Management.

Alan W. Pearson is the Director of the R\&D Research Unit at Manchester Business School and editor of the journal R\&D Management. His major area of interest is the Management of Research and Development and he has published widely on this subject. He is a Fellow of the Institute of Physics and in 1984 was awarded the Centennial Medal of the Institute of Electronic and Electrical Engineers for contributions to engineering management. In 1992 he received, jointly with Professor Brockhoff, the Max Planck Research Award from the Alexander von Humboldt Foundation. He was a visiting Professor at Kiel, Germany, from which he received an honorary $\mathrm{PhD}$ in 1993. Previous posts include, director of the MBA programme, Dean of the Faculty of Business Administration and Chair of the management committee for the recently formed Manchester Federal School of Business and Management. He is currently a visiting Professor at the University of Twente, the Netherlands.

Miguel Pina Cunha is an Assistant Professor at the Faculdade de Economia, Universidade Nova de Lisboa, in Lisbon, Portugal. He received his $\mathrm{PhD}$ from Tilburg University, The Netherlands, and is the current editor of Comportamento Organizacional e Gestão. Journals in which his research has appeared (or is forthcoming) include Organization Studies, Journal of Organizational Change Management, International Journal of Cross Cultural Management, International Journal of Management Reviews, SAM-Advanced Management Journal, International Journal of Innovation Management, and Journal of European Business Education. His research interests include organizational innovation and renewal, organizational improvisation and the effects of minimal structures on managing and organizing. 